\title{
SPECIFIC EFFECTS OF ESTROGEN ON GROWTH FACTOR AND MAJOR HISTOCOMPATIBILITY COMPLEX CLASS II ANTIGEN EXPRESSION IN RAT AORTIC ALLOGRAFT
}

Satoshi Saito, MD

Noboru Motomura, $\mathrm{MD}, \mathrm{PhD}$

Hong Lou, MD

Peter W. Ramwell, $\mathrm{PhD}$

Marie L. Foegh, MD, DSc

Sponsor:

Edward A. Lefrak, MD
Objective: Transplant arteriosclerosis is the major determinant for long-term survival of cardiac transplants. Estradiol treatment inhibits transplant arteriosclerosis. The objective of this study is to determine, in the absence of immunosuppression, the temporal effect of estradiol treatment on the expression of insulin-like growth factor, platelet-derived growth factor, basic fibroblast growth factor, and major histocompatibility complex class II antigen in rat aortic allografts. Methods: Orthotopic abdominal aortic allograft transplantation was performed in male rats with Brown-Norway rats used as donors and Lewis rats as recipients. The recipients $(n=50)$ were treated with estradiol 20 $\mu \mathrm{g} / \mathrm{kg}$ per day or placebo by osmotic minipump for 2 days before the operation and until they were put to death on postoperative days $1,3,7,14$, or 21 . The allografts were harvested and insulin-like growth factor, platelet-derived growth factor, basic fibroblast growth factor, and major histocompatibility complex class II antigen expression were determined by immunohistochemical staining. Myointimal thickening was measured by morphometric analysis. Results: In the placebo-treated group, insulin-like growth factor protein progressively increased in all three layers of the allograft, whereas platelet-derived growth factor protein peaked at day 3 and basic fibroblast growth factor protein increased only moderately. Estradiol treatment inhibited the continuous increase in insulin-like growth factor expression, the peak in plateletderived growth factor expression at day 3 , the moderate basic fibroblast growth factor increase at day 21 , and major histocompatibility complex class II antigen expression in all three layers of the allograft at day 21. Intimal thickening of allografts from estradiol-treated recipients was twofold to threefold less than that of the placebo-treated recipients at day 21. Conclusion: The development of transplant arteriosclerosis is associated with an early alloimmune response involving sustained increase in insulin-like growth factor expression. Estradiol treatment of the recipient inhibits transplant arteriosclerosis and suppresses insulin-like growth factor and major histocompatibility complex class II antigen expression but not platelet-derived growth factor or basic fibroblast growth factor in all three layers of the allograft during the early posttransplantation alloimmune rejection phase. (J Thorac Cardiovasc Surg 1997;114:803-10)
A ccelerated coronary arteriosclerosis in recipients of cardiac allografts is still the major cause of death or retransplantation after the first 3 months.

From the Department of Surgery and the Department of Physiology and Biophysics, Georgetown University Medical Center, Washington D.C.

Supported by the Ernst Schering Research Foundation and National Institutes of Health grant R01HL58896.

Read at the Seventy-seventh Annual Meeting of The American Association for Thoracic Surgery, Washington, D.C., May 4-7, 1997.
The pathogenesis may relate to an immune inflammatory reaction in the vascular wall involving transendothelial and adventitial inflammatory cell

Received for publication May 7, 1997; revisions requested June 30, 1997; revisions received July 30, 1997; accepted for publication July 30,1997

Address for reprints: Marie L. Foegh, MD, DSc, Georgetown University Medical Center, 4000 Reservoir Rd., N.W., Building D, Room 397, Washington, DC 20007.

Copyright (C) 1997 by Mosby-Year Book, Inc.

$0022-5223 / 97 \$ 5.00+0 \quad \mathbf{1 2 / 6 / 8 5 0 4 2}$ 
invasion accompanied by release of chemotactic and mitogenic cytokines and growth factors. These events promote proliferation and migration of smooth muscle cells into the subendothelial layer. Insulin-like growth factor (IGF-I) is increasingly recognized to stimulate lymphocyte production and function. ${ }^{1}$ Recently, we reported that IGF-I administered directly to the graft accelerates transplant arteriosclerosis ${ }^{2}$ and that coadministration of estradiol abrogates this effect. ${ }^{3}$

The protective role of estrogen hormone replacement therapy in cardiovascular disease in women is documented. ${ }^{4}$ Recently $\mathrm{we}^{5}$ found that estradiol treatment of the recipient inhibits allograft coronary myointimal hyperplasia and abolishes both IGF-I protein expression in the vascular wall and IGF-I mitogenic effects on allograft vessels ex vivo, thus further establishing a role for IGF-I in transplant arteriosclerosis.

Here, we describe the temporal relationship between the expression of growth factors (IGF-I, platelet-derived growth factor [PDGF-BB], and basic fibroblast growth factor [bFGF]) and myointimal hyperplasia after transplantation. We also show that estradiol, independently of cyclosporine A (INN: ciclosporin), inhibits growth factor, major histocompatibility complex (MHC) class II expression, and myointimal thickening. The aortic allograft model was used because immunosuppression is not required for grafts to serve as a functional conduit, thus avoiding a possible effect of cyclosporine A on transcriptional activity of the estradiol receptor ligand complex owing to the reported association of cyclophilin with the inactive estradiol receptor. ${ }^{6}$

\section{Materials and methods}

Animals. Male rats (250 gm) were purchased from Harlan Sprague Dawley (Indianapolis, Ind.) and housed in a facility approved by the American Association for Accreditation of Laboratory Animal Care that was maintained at $20^{\circ} \mathrm{C}$ with scheduled 12-hour light cycles. The animals were fed rat chow diet ad libitum and acclimatized at least for 1 week before use. All animals received humane care in compliance with the "Principles of Laboratory Animal Care" formulated by the National Society for Medical Research and the "Guide for the Care and Use of Laboratory Animals" prepared by the National Institute of Laboratory Animal Resources and published by the National Institutes of Health (NIH Publication No. 85-23, revised 1985).

Transplantation procedure. Orthotopic transplantation of abdominal aortic allografts was performed with Brown-Norway rats used as donors and Lewis rats as recipients as previously described. ${ }^{3}$ In short, donors and recipients were anesthetized with ketamine, $80 \mathrm{mg} / \mathrm{kg}$, and xylazine, $10 \mathrm{mg} / \mathrm{kg}$. The donor abdominal aorta was isolated and resected after intravenous injection of heparin, 200 units $/ \mathrm{kg}$. The recipient aorta was transected between two microvascular clamps (Micro Vessel Clip, Biomedical Research Instruments, Rockville, Md.), and the donor aorta was transplanted end to end with intermittent 10-0 nylon sutures (Accurate Corp., Westbury, N.Y.). The anastomosis was performed with the aid of a surgical microscope (Olympus Corp., Lake Success, N.Y.).

Experimental groups. The recipients were randomly assigned to two groups: The group treated with estradiol$17 \beta(n=25)$ received a $20 \mu \mathrm{g} / \mathrm{kg}$ per day subcutaneous dose of estradiol cypionate (Depo-Estradiol, The Upjohn Company, Kalamazoo, Mich.) continuously by an osmotic minipump (Alza Corp., Palo Alto, Calif.) from 2 days before transplantation until the animals were put to death. The placebo-treated group $(n=25)$ received an equal volume of placebo. The animals were put to death on posttransplantation days $1(n=6), 3(n=10), 7(n=12)$, $14(n=12)$, or $21(n=10)$, at which time blood was drawn for determination of serum estradiol levels.

Preparation of the aortic allograft. The recipients were put to death under deep anesthesia after heparin administration. The aortic allografts were isolated and pressureperfused at $80 \mathrm{~mm} \mathrm{Hg}$ for 30 minutes with saline solution followed by formalin tissue fixative (Histochoice, Amresco Inc., Solon, Ohio). The grafts were cut horizontally into three segments, which were embedded in paraffin. Sections of $6 \mu \mathrm{m}$ thickness were cut from each block for immunohistochemistry or stained with either hematoxylin-eosin or an elastin stain for histologic and morphometric evaluation, respectively.

Immunohistochemistry. The antibodies mentioned below were used as primary antibodies; their dilution ratio or concentration is given in parentheses. The monoclonal antibody for IGF-I $(1: 10,000)(10 \mu \mathrm{g} / \mathrm{ml})$ was kindly provided by Dr. P. Delafontaine at Emory University (Atlanta, Ga.). The monoclonal antibodies for plateletderived growth factor-BB (PDGF-B) (1:300) and basic fibroblast growth factor (bFGF) type A (1:300) were purchased from Upstate Biotechnology Inc. (UBI, Lake Placid, N.Y.). MHC class II antigen expression was determined at day 21 by using the OX6 monoclonal antibody (Harlan Sera-lab Ltd., Sussex, United Kingdom) at 1:1000 dilution. The immunohistochemistry staining was performed at room temperature with the use of the Histostain SP Kit (Zymed, Inc., South San Francisco, Calif.) according to the protocol of the manufacturer. After dewaxing with xylene and rehydration with ethanol, the sections were placed in $3 \%$ hydrogen peroxide $/ 100 \%$ methanol (Sigma Chemical Co., St. Louis, Mo.) for 20 minutes, washed with phosphate-buffered saline solution (Biofluids Inc., Rockville, Md.) three times for 2 minutes, and then incubated in serum-blocking solution for 1 hour. The primary antibody was applied for 2 hours, washed with phosphate-buffered saline solution, and then incubated with biotin-labeled secondary antibody for 1 hour (Sigma). Thereafter, a streptavidin-peroxidase reaction system was applied, and hematoxylin (Sigma) was added for counterstaining.

Grading of the immunohistochemical staining. The intensity of the immunohistochemical staining in intima, 

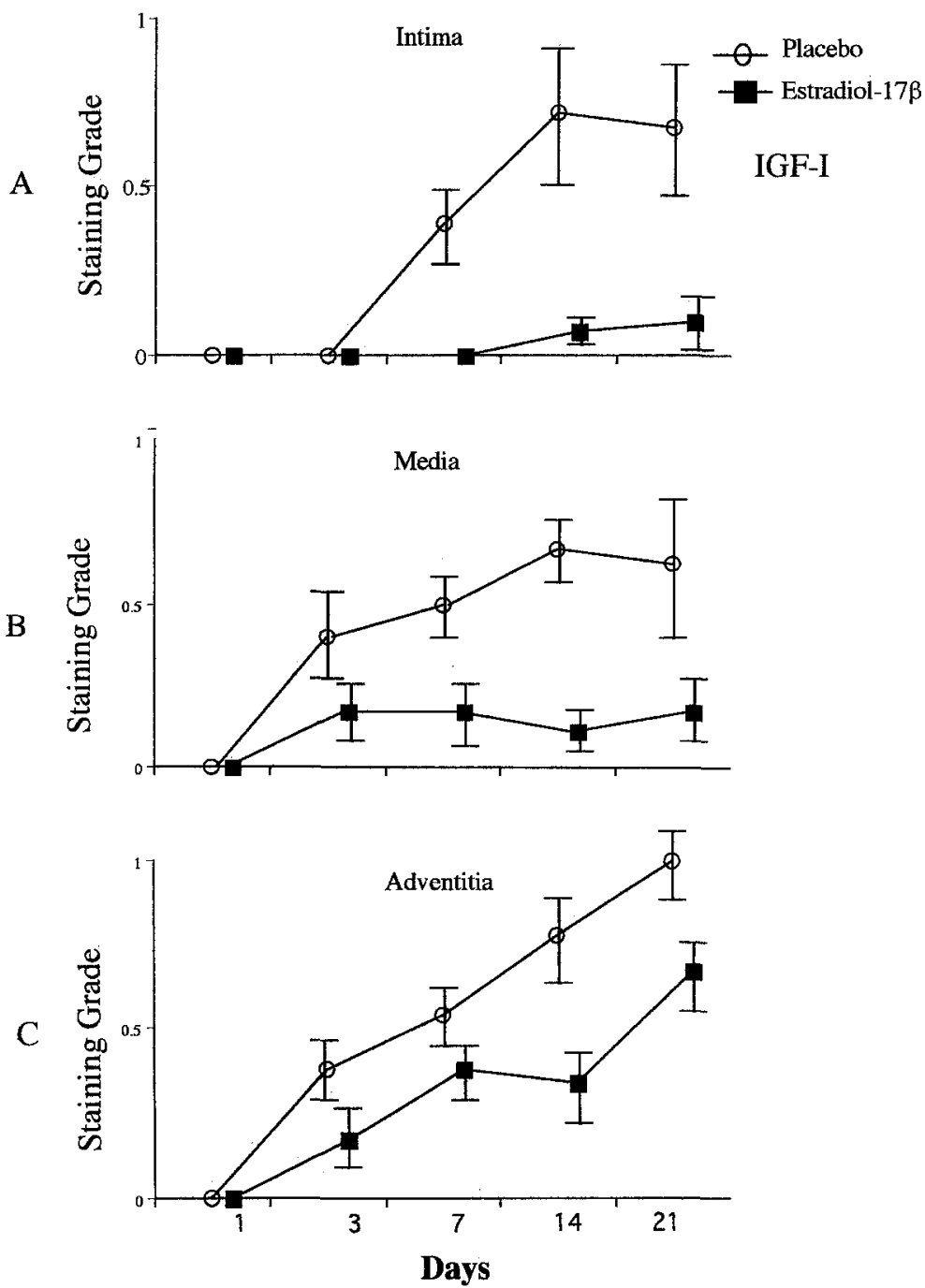

Fig. 1. Posttransplantation IGF-I expression in rat aortic allografts from recipients treated with either estradiol-17 $\beta$ or placebo. The expression of IGF-I is determined by grading (on a scale of 0 to 3 ) the degree of immunohistochemistry staining in intima (A), media (B), and adventitia (C). Three histologic cross sections from each allograft on day $1.3,7,14$, and 21 after transplantation were used. The data are expressed as mean \pm standard error of the mean. Estradiol- $17 \beta$ vs. placebo: $\boldsymbol{\Lambda}$, day $7, p=0.04$; day $14, p=$ 0.0008 ; day $21, p=0.0003$. B, day $3, p=0.2$; day $7, p=0.09$; day $14, p=0.003$; day $21, p=0.01$. C, day $3, p=0.3$; day $7, p=0.03$; day $14, p=0.003$; day $21, p=0.02$.

media, and adventitia was graded by a scoring system from 0 to 3 : no staining $=0$; weak staining, showing a couple of patchy stained loci $=1$; patchy staining in less than $50 \%$ of the area $=2$; and more than $50 \%$ of the area strongly stained $=3$. Three cross sections from each allograft were graded and the scores were averaged. This was done for all time points in both the estradiol and placebo treatment groups. The scoring was performed independently by two investigators blinded to the treatment groups.

Morphometric analysis. The degree of intimal thickening was determined by computed morphometry (The Morphometer, Woods Hole Educational Associates, Woods
Hole, Mass.). Three horizontal sections from each allograft were examined. The intimal thickness was expressed as the area of myointima over the total vessel area $\times 100 \%$ as previously described. ${ }^{7}$ All measurements were done independently by two investigators blinded to treatment groups.

Serum estradiol. Blood samples were obtained when the animals were put to death. The samples were centrifuged and the serum was stored at $-20^{\circ} \mathrm{C}$. Estradiol-17 $\beta$ was measured by radioimmunoassay (Diagnostic Products Corp., Los Angeles, Calif.).

Statistical analysis. The data are expressed as means \pm standard error of the mean. Differences among the groups were compared by a two-way factorial analysis of variance 
Table I. Posttransplantation PDGF-BB expression in rat aortic allografts from recipients treated with either estradiol- $17 \beta$ or placebo

\begin{tabular}{|c|c|c|c|c|c|c|c|c|c|}
\hline \multirow[b]{2}{*}{ Day } & \multicolumn{3}{|c|}{ Intima } & \multicolumn{3}{|c|}{ Media } & \multicolumn{3}{|c|}{ Adventitia } \\
\hline & Placebo & Estradiol-17 $\beta$ & $\begin{array}{c}p \\
\text { Value } \\
\end{array}$ & Placebo & Estradiol-17 $\beta$ & $\begin{array}{c}p \\
\text { Value }\end{array}$ & Placebo & Estradiol-17 $\beta$ & $\begin{array}{c}p \\
\text { Value }\end{array}$ \\
\hline 1 & 0 & 0 & & 0 & 0 & & 0 & 0 & \\
\hline 3 & 0 & 0 & & $0.22 \pm 0.10$ & 0 & 0.2 & $0.50 \pm 0.11$ & $0.17 \pm 0.10$ & 0.03 \\
\hline 7 & $0.17 \pm 0.08$ & $0.10 \pm 0.10$ & 0.3 & $0.14 \pm 0.08$ & $0.10 \pm 0.08$ & 0.2 & $0.38 \pm 0.10$ & $0.17 \pm 0.09$ & 0.9 \\
\hline 14 & $0.15 \pm 0.08$ & $0.10 \pm 0.07$ & 0.6 & $0.10 \pm 0.06$ & $0.10 \pm 0.05$ & 0.7 & $0.42 \pm 0.15$ & $0.28 \pm 0.09$ & 0.4 \\
\hline 21 & $0.27 \pm 0.10$ & $0.23 \pm 0.10$ & 0.7 & $0.10 \pm 0.06$ & $0.12 \pm 0.06$ & 0.9 & $0.33 \pm 0.11$ & $0.25 \pm 0.11$ & 0.6 \\
\hline
\end{tabular}

The expression of PDGF-BB was determined by grading on a scale of 0 to 3 the degree of immunohistochemistry staining in intima, media, and adventitia. Three histologic cross sections from each allograft on days $1,3,7,14$, and 21 after transplantation were used. The data are expressed as means \pm standard error of the mean.

followed by multiple comparison analysis. When the variances between the groups were found not to differ by the F-test, Fisher's test was used for the multiple comparison analysis. The differences were considered statistically significant at $p<0.05$.

\section{Results}

\section{Expression of IGF-I in the aortic allograft}

Intima. IGF-I expression was present in both the placebo- and estradiol-17 $\beta$-treated groups from days 7 and 14, respectively. Significantly less IGF-I protein was present at day 14 in the estradiol- $17 \beta-$ treated group than in the placebo-treated group $(0.07 \pm 0.04$ vs $0.72 \pm 0.20, p=0.0008)$. This significant difference in IGF-I expression was maintained at day $21(0.10 \pm 0.08$ vs $0.68 \pm 0.17$, placeboand estradiol-treated groups, respectively, $p=$ 0.0003 ) (Fig: 1, $A$ ).

Media. The expression of IGF-I in the allograft from the estradiol-17 $\beta$-treated group was significantly less than in the allograft from the placebotreated group both at day $14(0.11 \pm 0.07$ vs $0.67 \pm$ $0.12, p=0.003)$ and at day $21(0.17 \pm 0.12$ vs $0.63 \pm$ $0.20, p=0.01$ ) (Fig. 1, $B$ ).

Adventitia. IGF-I expression in the allografts from the placebo-treated group increased continuously from days 3 to 21, whereas IGF-I expression in the allografts from the estradiol-treated group was significantly less at day $7(0.54 \pm 0.10 \mathrm{vs} 0.38 \pm 0.08$, $p=0.03)$, day $14(0.78 \pm 0.12$ vs $0.34 \pm 0.09, p=$ $0.003)$, and day $21(1.0 \pm 0.09$ vs $0.67 \pm 0.09, p=$ 0.02) (Fig. 1, C).

Expression of PDGF-BB. In the placebo group, PDGF-BB expression peaked at day 3 in the adventitia and medial layers whereas the expression continuously increased in the intima. In the estradiol-17 $\beta$-treated group, PDGF-BB expression was present from day 7 in the intima and media and peaked at day 14 in the adventitia. At day 3, significantly less PDGF-BB expression was seen in the adventitia of allografts from the estradiol- $17 \beta$-treated group compared with allografts from the placebo-treated group $(0.17 \pm 0.10 \mathrm{vs}$ $0.50 \pm 0.11, p=0.03$ ) (Table I). No significant differences were observed at any other time point. Immunostaining for PDGF-BB in the allografts from both the placebo- and estradiol- $17 \beta$-treated groups is shown in Table I.

Expression of bFGF. In the placebo group, bFGF expression was seen at day 3 in the media and adventitia and at day 7 in the intima, and the expression continuously increased in all three layers. In the estradiol-17 $\beta$-treated group, bFGF expression continuously increased in the intima and adventitia. At day 21, significantly less bFGF expression was seen in the media of allografts from the estradiol-17 $\beta$-treated group compared with allografts from the placebo-treated group $(0.20 \pm 0.08$ vs $0.03 \pm 0.03, p=0.002$ ) (Table II). No significant differences were observed at any other time point. Immunostaining for bFGF in the allografts from both the placebo- and estradiol-17 $\beta$-treated groups is shown in Table II.

\section{Expression of MHC class II antigen}

Intima. At day 21 the MHC class II expression was up-regulated in the allografts from the placebotreated group whereas the antigen was significantly depressed in the estradiol-17 $\beta$-treated group ( $1.42 \pm 0.43$ vs $0.14 \pm 0.07, p<0.0001)$.

Media. MHC class II antigen expression was present at day 21 in allografts from the placebotreated group. In contrast, MHC class II antigen was absent in the allografts from the estradiol-17 $\beta$ treated group $(0.75 \pm 0.028$ vs $0.00, p<0.0001)$.

Adventitia. The expression of MHC class II antigen in the allograft from the estradiol- $17 \beta$-treated 
Table II. Posttransplantation bFGF expression in rat aortic allografts from recipients treated with either estradiol-17 $\beta$ or placebo

\begin{tabular}{|c|c|c|c|c|c|c|c|c|c|}
\hline \multirow[b]{2}{*}{ Day } & \multicolumn{3}{|c|}{ Intima } & \multicolumn{3}{|c|}{ Media } & \multicolumn{3}{|c|}{ Adventitia } \\
\hline & Placebo & Estradiol-17 $\beta$ & $\begin{array}{c}p \\
\text { Value }\end{array}$ & Placebo & Estradiol $-17 \beta$ & $\begin{array}{c}p \\
\text { Value }\end{array}$ & Placebo & Estradiol-17\% & $\begin{array}{c}p \\
\text { Value }\end{array}$ \\
\hline 1 & 0 & 0 & & 0 & 0 & & 0 & 0 & \\
\hline 3 & 0 & 0 & & $0.16 \pm 0.06$ & 0 & 0.1 & $0.14 \pm 0.06$ & $0.11 \pm 0.06$ & 0.7 \\
\hline 7 & $0.10 \pm 0.05$ & $0.10 \pm 0.06$ & 0.7 & $0.06 \pm 0.04$ & 0 & 0.3 & $0.22 \pm 0.06$ & $0.19 \pm 0.06$ & 0.8 \\
\hline 14 & $0.18 \pm 0.07$ & $0.09 \pm 0.05$ & 0.2 & $0.10 \pm 0.05$ & $0.03 \pm 0.03$ & 0.3 & $0.33 \pm 0.07$ & $0.30 \pm 0.06$ & 0.8 \\
\hline 21 & $0.29 \pm 0.09$ & $0.27 \pm 0.08$ & 0.9 & $0.20 \pm 0.08$ & $0.03 \pm 0.03$ & 0.002 & $0.48 \pm 0.12$ & $0.33 \pm 0.10$ & 0.1 \\
\hline
\end{tabular}

The expression of bFGF was determined by grading on a scale of 0 to 3 the degree of immunohistochemistry staining in intima, media, and adventitia. Three histologic cross sections from each allograft on days 1, 3, 7, 14, and 21 after transplantation were used. The data are expressed as means \pm standard error of the mean.

group was significantly less than that of the placebotreated group at day 21 ( $2.5 \pm 0.22$ vs $0.25 \pm 0.10$, $p<0.0001$ ).

Morphometric analysis of the aortic allograft. By light microscopy, intimal thickening was visible at day 7 and measurable at days 14 and 21. The intimal thickening in the allografts from estradiol-17 $\beta$ treated recipients was twofold to threefold less than the intimal thickening in the allografts from placebo-treated recipients at day $21(9.5 \% \pm 2.0 \%$ vs $24.9 \% \pm 3.6 \%, p=0.001$, Fig. 2 ).

Serum estradiol. Serum estradiol- $17 \beta$ concentration when the animals were put to death was elevated in the estradiol-17 $\beta$-treated animals to $147.1 \pm 17.45 \mathrm{pg} / \mathrm{ml}$ compared with $8.42 \pm 2.14$ $\mathrm{pg} / \mathrm{ml}$ in the placebo-treated control group $(p=$ 0.001 ). There was no significant difference in serum estradiol- $17 \beta$ values on days $1,3,7,14$, and 21 in the estradiol-treated animals.

\section{Discussion}

In the absence of immunosuppression, treatment of recipients with estradiol- $17 \beta$ prevents the progressive increase in allograft IGF-I expression after transplantation. There was little or no effect on PDGF-BB and bFGF expression, although myointimal thickening was significantly inhibited. The allograft from the placebo group exhibited progressive expression of IGF-I from day 3 in adventitia and peaked at day 14 in the intima and media, at which time allograft myointimal hyperplasia became measurable. This is in contrast to allografts from the estradiol-17 $\beta$-treated recipients, wherein significantly less IGF-I expression and myointimal hyperplasia was observed. These data are in accord with our previous finding that rat aortic allografts exposed to IGF-I before grafting exhibited accelerated intimal thickening that was attenuated by estradiol$17 \beta$ treatment of the recipients. ${ }^{2,3}$

Immunologic and nonimmunologic injury either directly or indirectly predisposes an allograft to proinflammatory cytokines leading to endothelial injury. ${ }^{7}$ Activated endothelial cells produce several growth factors that induce the transformation of smooth muscle cells to the synthetic phenotype that replicates and migrates, ${ }^{8}$ allograft arteriosclerosis progresses, and graft function deteriorates. Ischemic, reperfusion, and immune injury are common to the allograft and up-regulate expression of IGF-I, bFGF, and PDGF-BB in both smooth muscle and endothelial cells. The normal vessel wall does not express any of these growth factors, and their absence is also observed in our study 24 hours after transplantation (day 1). However, up-regulation of the three growth factors is seen on day 3 after transplantation. Ischemia and reperfusion injury is known to cause a peak in PDGF-BB and bFGF on day 3 and in IGF-I on days 4 to $5 .^{9-11}$ The progressive increase in IGF-I beyond day 5 is induced by the alloimmune response. PDGF-BB does not exhibit a progressive increase. The continuous expression may be due to the initial ischemia and reperfusion injury or may be sustained by the alloimmune activity. There is a moderate but continuous increase in bFGF, unlike that after ischemic injury, suggesting that the alloimmune response is directly or indirectly involved in the expression of bFGF.

IGF-I is a progressive growth factor that acts primarily on the $\mathrm{G} 1$ phase of the cell cycle to promote entry into the $\mathrm{S}$ phase, ${ }^{12}$ whereas PDGF-BB is a competence factor unable to cause mitogenesis without IGF-I. In human coronary atherectomy specimens, IGF-I is more intensely expressed in the synthetic than in contractile smooth 


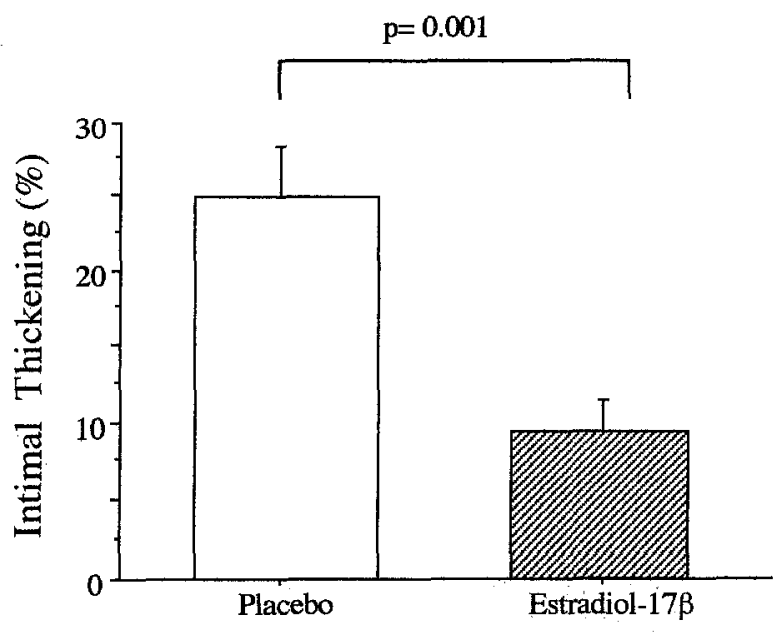

Fig. 2. Intimal thickening of allograft aorta from the placebo-treated group (open bar) and from the estradiol$17 \beta$-treated group (hatched bar) on day 21 after transplantation. Intimal thickening is expressed as a percentage of myointimal area over total vessel area (area within external elastic lamina). Three histologic cross sections from each allograft on days 1, 3, 7, 14, and 21 after transplantation were used. Estradiol-17 $\beta$ treatment significantly $(p=0.001)$ reduced allograft transplant arteriosclerosis. The data are expressed as mean \pm standard error of the mean.

muscle cells, suggesting that IGF-I expression is a function of the proliferative state of smooth muscle cells generating autocrine stimulation of growth. ${ }^{13}$ This mitogenic effect of IGF-I is abolished by coincubation with a specific monoclonal anti-IGF-I antibody confirming the specific mitogenic role of IGF-I in smooth muscle cell proliferation. ${ }^{5}$ This mitogenic effect also applies to the allograft in which a single local application of IGF-I accelerates transplant arteriosclerosis in vivo. ${ }^{2}$ Recent studies by others support the notion that blocking IGF-I or IGF-I receptor will decrease smooth muscle cell proliferation. For example, an antisense IGF-I receptor, oligonucleotide, abrogates the mitogenic effects of both PDGF-BB and bFGF in smooth muscle cell cultures. ${ }^{14}$ Our present study demonstrates that estradiol treatment prevents IGF-I up-regulation, suggesting that attenuation of IGF-I expression is linked to inhibition of transplant arteriosclerosis. We have previously shown that estradiol treatment inhibits IGF-I expression in the allograft coronary artery 6 weeks after transplantation ${ }^{5}$ in a rabbit transplant model in which the immunosuppressant cyclosporine A was given daily to avoid acute rejection. The current data show that in the absence of cyclosporine A estradiol prevents the continuous and substantial up-regulation of IGF-I, supporting the hypothesis that IGF-I plays an important role in transplant arteriosclerosis.

The role of IGF-I may relate to its effects on the immune system, ${ }^{1}$ where it has a significant role in the maturation of lymphocytes in the bone marrow and assists their function in the periphery. In rodents, treatment with IGF-I can restore age-related thymic involution, increase lymphocyte number and activity, improve reduced antibody response to an antigen challenge, and accelerate lymphoid clonal expansion after immune injury. ${ }^{15}$ In this present study, allografts from placebo-treated recipients exhibited progressive IGF-I expression in all three layers of vascular allograft with ongoing acute rejection. Estradiol-17 $\beta$ inhibition of IGF-I expression may diminish both IGF-I-induced mitogenic effects and its stimulating effect on lymphocytes and their function.

In this present study, significant reduction by estradiol-17 $\beta$ of transplant arteriosclerosis was associated with inhibition of inducible vascular MHC class II antigen expression. We ${ }^{16}$ recently discovered that estradiol- $17 \beta$ abolishes MHC class II antigen expression in the cardiac allograft in recipients immunosuppressed with cyclosporine A. Up-regulation of both constitutive and inducible MHC class II antigen expression plays a central role in immune activation associated with transplant arteriosclerosis. The role of IGF-I in MHC class II antigen expression is not known at present. Interferon- $\gamma$ (INF- $\gamma$ ) is the known inducer of MHC class II expression in allograft rejection ${ }^{17}$ and thus may be a mediator of transplant arteriosclerosis. Interestingly, the INF- $\gamma$ gene is up-regulated by estradiol after binding of the estrogen receptor to the estrogen receptor response element, suggesting that suppression of MHC class II expression is not associated with the IFN- $\gamma$ gene but with the MHC class II gene or the class II transactivating gene. ${ }^{18}$

The lack of consistent suppression of PDGF-BB and bFGF expression in the estradiol-treated allograft, in the face of significant inhibition of transplant arteriosclerosis, suggests that these growth factors may be of less importance in transplant arteriosclerosis than in native artery atherosclerosis. Our results suggest that PDGF-BB is involved in the ischemia-reperfusion injury phase by inducing IGF-I receptor on lymphocytes, smooth muscle cells, and macrophages, thus augmenting the alloimmune-mediated myointimal thickening in the early phase. 
Autocrine or paracrine production of IGF-I is believed to be necessary for PDGF-BB to exert mitogenic effects on smooth muscle cells and fibroblasts. ${ }^{19}$ This suggests that estradiol- $17 \beta$ inhibition of PDGF-BB expression on posttransplantation day 3 in the media is an indirect effect through suppression of IGF-I expression.

In this present study, estradiol-17 $\beta$ treatment of recipients did not affect the expression of bFGF on allograft aorta in intima and adventitia and only inhibited bFGF expression on day 21 in the media. Out results indicate that estradiol- $17 \beta$ has no direct inhibitory effects on bFGF expression in rat aortic allografts. IGF-I is also reported to increase bFGF-induced mitogenesis and up-regulate $b F G F$ receptor in vascular smooth muscle cells. ${ }^{20}$ The temporal inhibition of bFGF expression in the media at day 21 in this study may be due to an indirect effect through estradiol-17 $\beta$ suppression of IGF-I expression.

\section{Conclusion}

In the absence of immunosuppression, estradiol treatment of recipients prevents a progressive increase in IGF-I and MHC class II antigen expression, but not PDGF-BB or bFGF expression in all three layers of the rat aortic allograft. The accompanying inhibition of transplant arteriosclerosis lends further support for the suggestion that IGF-I expression has a crucial role in the early phase of acute rejection.

\section{REFERENCES}

1. Ross C. Somatogenic hormones and IGF-I: stimulation of proliferation and immune function. Endocr Rev 1997;18:15779.

2. Motomura N, Lou H, Maurice P, Foegh ML. Transplant arteriosclerosis of rat aorta is accelerated by insulin-like growth factor-I. Transplantation 1997;63:932-6.

3. Motomura N, Lou H, Hong M, Tsutsumi T, Foegh ML. Local administration of estrogen inhibits transplant arteriosclerosis in rat aorta accelerated by topical exposure to IGF-I. Transplant Proc 1997;29:1118-20.

4. Kofnek SD. Postmenopausal hormone replacement therapy and cardiovascular risk reduction. Drugs 1994;47(suppl 2):1624.

5. Lou H, Zhao Y, Delafontaine P, Kodama T, Katz N, Foegh ML. Estrogen effects on insulin-like growth factor-1 (IGF-I) induced cell proliferation and IGF-I expression in native and allograft vessels. Circulation 1997;96:927-33.

6. Segnitz B, Gehring U. Subunit structure of the nonactivated human estrogen receptor. Proc Natl Acad Sci U S A 1995; 92:2179-83.

7. Foegh ML, Virmani R. Molecular biology of intimal proliferation. In: Yacoub M, Pepper JR, editors. Annual of cardiac surgery-illustrated. 7th ed. London: Current Science Ltd; 1994. p. 53-65.

8. Aziz S, McDonald O, Gohra $\mathrm{H}$. Transplant arterial vasculopathy: evidence for a dual pattern of endothelial injury and the source of smooth muscle cells in lesions of intimal hyperplasia. J Heart Lung Transplant 1995;14(part 2):S123-36.

9. Howell M, Frystyk J, Orskov H, Flyvjerg A, Gronbaek H, Foegh ML. Lanreotide, a somatostatin analogue, reduces insulin-like growth factor I accumulation in proliferating aortic tissue in rabbit in vivo: a preliminary study. Eur $\mathrm{J}$ Endocrinol 1994;130:422-5.

10. More SR, Brack MJ, Underwood MJ, Gershlick AH. Growth factor persistence after vessel wall injury in a rabbit angioplasty model. Am J Cardiol 1994;73:1031-2.

11. Cercek B, Fishbein MC, Forrester JS, Helfant RH, Fagin JA. Induction of insulin-like growth factor I messenger RNA in rat aorta after balloon denaduation. Circ Res 1990;66:175560 .

12. Stiles CD, Capone GT, Scher CD, Antoniades HN, Van Wyk JJ, Pledger WJ. Dual control of cell growth by somatomedins and platelet derived growth factor. Proc Natl Acad Sci U S A 1979;76:1279.

13. Grant M, Wargovich G, Ellis E, Caballero S, Mansour M, Pepine C. Localization of insulin-like growth factor I and inhibition of coronary smooth muscle cell growth by somatostatin analogues in human coronary smooth cells. Circulation 1994;89:1511-7.

14. Delafontaine P, Meng XP, Du J. Regulation of vascular smooth muscle cell insulin-like growth factor-I receptors by phosphorothioate oligonucleotides: effects on growth and evidence that sense targeting at the ATG site increase receptor expression. J Biol Chem 1995;270:1995.

15. Clark R, Strasser J, McCabe S, Robbins K, Jardieu P. Insulin-like growth factor-I stimulation of lymphopoiesis. J Clin Invest 1993;92:540-8.

16. Lou H, Kodama T, Xhao YY, Maurice P, Wang YN, Katz N, et al. Inhibition of transplant coronary arteriosclerosis in rabbits by chronic estradiol treatment is associated with abolition of MHC class II antigen expression. Circulation 1996;94:3355-61.

17. Steimle V, Siegrist C-A, Mottet A, Lisowska-Grospierre BBM. Regulation of MHC class II expression by interferon- $\gamma$ mediated by the transactivator gene CIITA. Science 1994; 264:1920-1.

18. Fox FS, Bond BL, Parslow TG. Estrogen regulates the IFN-gamma promoter. J Immunol 1991;146:4362-7.

19. Arnqvist HJ, Bornfeldt KE, Chen Y, Lindstrom T. The insulin-like growth factor system in vascular smooth muscle: interaction with insulin and growth factor. Metabolism 1995; 44:58-66.

20. Reape TJ, Kankzler JM, Ward JP, Thomas CR. IGF-I increases bFGF-induced mitogenesis and upregulates FGFR-1 in rabbit vascular smooth muscle cells. Am J Physiol 1996;270:1141-8.

\section{Discussion}

Mr. Magdi Yacoub (London, England). Induction of class II MHC antigen expression and infiltration by macrophages are relatively late events. What do you think about the mechanism of the action of estradiol? Have you 
looked at induction of nitric oxide synthase, for example, or some cytokines?

Dr. Saito. MHC class expression is inducible in many MHC class II negative cells, such as smooth muscle cells and endothelial cells, by a variety of stimuli, particularly INF- $\gamma$. Both constitutive and inducible gene expression is controlled primarily by the recently identified class II transcription activated gene, CIITA, so we are speculating that estrogen is directly affecting these genes.

Dr. Hikaru Matsuda (Osaka, Japan). Have you tested this experiment in the other matching model of the animals with a different combination of the MHC class $\mathrm{I}$ antigen?

Second, we have shown that there are some triggers that occur during the early period after transplantation to promote coronary atherosclerosis. Have you tried giving estradiol- $17 \beta$ only until 5 days or so and seeing what happens afterward?

Dr. Saito. The combination of donor and recipient strains used here is very much allogenic, probably the strongest allogenic chronic rejection model. We did not use other combinations.

We have shown that at 6 weeks after transplantation in the rabbit model, estradiol completely abolished the expression of MHC class II antigen in all three areas of intima, media, and adventitia. We have not tried shortterm treatment like 5 days.

Dr. Charles A. Yankah (Berlin, Germany). Did you observe in your series whether there were some changes or inhibition of migration of the myofibroblasts onto the endothelial surfaces? Migration of myofibroblasts is an important mechanism for the induction of arteriosclerosis.

Dr. Saito. I understand that migration from the medial area to the intima and perhaps of myofibroblast from the adventitia is a very important mechanism for the development of intimal hyperplasia. We did not study migration as such, but myointimal thickening was reduced by estradiol.

\section{Bound volumes available to subscribers}

Bound volumes of The Journal of Thoracic and Cardiovascular Surgery are available to subscribers (only) for the 1997 issues from the Publisher, at a cost of $\$ 110.50$ for domestic, $\$ 139.64$ for Canadian, and $\$ 130.50$ for international subscribers for Vol. 113 (January-June) and Vol. 114 (July-December). Shipping charges are included. Each bound volume contains a subject and author index and all advertising is removed. Copies are shipped within 60 days after publication of the last issue of the volume. The binding is durable buckram with the Journal name, volume number, and year stamped in gold on the spine. Payment must accompany all orders. Contact Mosby-Year Book, Inc., Subscription Services, 11830 Westine Industrial Drive, St. Louis, Missouri 63146-3318, USA; phone $800-453-4351$ or 314-453-4351.

Subscriptions must be in force to qualify. Bound volumes are not available in place of a regular Journal subscription. 